\title{
Comparative effectiveness of extracorporeal shock wave therapy, local corticosteroid injection, and conventional physiotherapy in treatment of chronic lateral epicondylitis
}

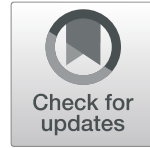

Mona Mohamed Mohamed Ismael*, Mona Mahmoud Arafa, Abeer Ahmed Kadry El Zohiery and Soha Eldessouki Ibrahim

\begin{abstract}
Background: Lateral epicondylitis (LE) is a popular overuse syndrome involving the forearm's extensor tendons. Corticosteroid (CS) injection is the popular injection used for management of LE. Extracorporeal shockwave therapy (ESWT) is a noninvasive alternative inducing the neovascularization, tendon repairing, and decreasing pain. Our study aimed to compare the effectiveness of ESWT versus local CS injection versus conventional physiotherapy (PT) in management of chronic LE.

Results: Our results revealed that the three groups displayed a significant decrease of VAS score, decrease of PRTEE score, and increase of grip strength compared to baseline $(P<0.05)$ at 4 weeks and 12 weeks of follow-up. However, there was a significant decrease of VAS score in ESWT and CS groups more than PT group at 4 weeks follow-up $(P<0.05)$ while ESWT group displayed a considerable improvement in functional disability score (decrease in PRTEE score) more than CS and PT groups at 4 and 12 weeks of follow-up $(P<0.05)$, with no considerable change in HGS between the three groups.

Conclusion: ESWT, local CS injection, and conventional PT were efficient in management of chronic LE at 12 weeks of follow-up but ESWT had a higher effect decreasing pain and improving functional disability in daily life activity at short and long term follow-up.
\end{abstract}

Keywords: Lateral epicondylitis, Extracorporeal shock wave therapy, Corticosteroid injection, Physiotherapy

\section{Background}

Lateral epicondylitis (LE) or tennis elbow is one of the most common overuse injuries affecting the common origin of the extensor tendons of the forearm with prevalence of $1-3 \%$ of the population. It mostly occurs in patients whose activities require strong gripping or repetitive wrist movements [1].

Clinical diagnosis is made by the history and physical assessment that is tenderness over the lateral humeral

\footnotetext{
* Correspondence: monamohmed11289@gmail.com

Physical Medicine, Rheumatology and Rehabilitation Department, Faculty of Medicine, Ain Shams University, 33 El-Salam Street, Helwan, Cairo, Egypt
}

epicondyle which increases with resisted dorsiflexion of the wrist [2].

Conservative treatments including rest, medications, orthotics, physical modalities, and exercises have documented successful outcomes at rates of 89 to 90 percent [3].

Corticosteroid (CS) injection seems to be efficient and harmless in the short-term therapy of LE. But, there is no sufficient proof to its long-term effectiveness [4].

Extracorporeal shockwave therapy (ESWT) is recently applied in several musculoskeletal diseases. The mechanism of action depends on stimulation of the tendon healing by encouraging neovascularization, 
with accompanying hyper-stimulation analgesia. Some studies have reported significant improvement in pain and functional scores after ESWT $[5,6]$.

Braces aims to minimize stress to the extensor muscles of the forearm by suppling a counterforce and permitting the injured tendons to rest and heal [7].

Although, comparisons among treatment modalities have been mentioned in the literature with incompatible results and no single modality has been confirmed to be the most effective $[8,9]$. So, the study aimed to compare the effectiveness of ESWT versus local CS injection versus conventional physiotherapy in LE.

\section{Methods}

The study included forty-five patients diagnosed as LE between April 2018 and January 2019, from the outpatient clinic of Physical Medicine, Rheumatology and Rehabilitation Department, Ain Shams University Hospital. Written informed consents were taken from all participants. Figure 1 shows the flowchart concerning patients' registration. All patients were acquainted about the procedure of the study.

Sociodemographic data of the patients were registered. Pain intensity on resisted dorsiflexion of wrist was recorded by a visual analog scale (VAS), and the forearm pain and functional disability were recorded by patientrated tennis elbow evaluation questionnaire (PRTEE). Pain-free grip strength was recorded using a hand dynamometer [10]. Mean of three evaluations was measured regarding Roberts et al. [10].

Forty-five patients were randomly assigned to receive either ESWT sessions or steroid injection, or conventional physiotherapy as in Fig. 1.

Group-I $(n=15)$ received a single injection by a mixture composed of methylprednisolone acetate (20 $\mathrm{mg})$ and $0.6 \mathrm{ml}$ of lidocaine. Group II $(n=15)$ received physical modalities including transcutaneous electrical nerve stimulation (TENS) $(20 \mathrm{~min})$, pulsed ultrasound therapy $(50 \%$ duty cycle $)\left(1 \mathrm{~W} / \mathrm{cm}^{2}, 3\right.$ $\mathrm{MHz}, 5 \mathrm{~min}$ ), and local massage and stretching exercises for the common extensor origin for twelve sessions (3 sessions per week). Group III $(n=15)$ received ESWT sessions (pressure $1.6 \mathrm{bar}$, frequency $16 \mathrm{~Hz}, 2000$ shocks) for 3 sessions (1-week interval between sessions). All patients of the three groups were instructed to put on counterforce band and to stop analgesics for 3 months until reassessment.

Statistical analysis was performed with the Statistical Package for Social Science (IBM SPSS) version 23. The quantitative variables were expressed as mean, standard deviations and ranges for parametric data, and median with range for non-parametric. The qualitative data were offered as numbers and percentages. Comparison between groups were done with one-way ANOVA, Kruskal-Wallis, repeated measures ANOVA test, chi-square test, and post hoc analysis. Statistical significance at $p \leq 0.05$.

\section{Results}

Demographic data of the participants are presented in Table 1 . The three groups were nearly matched to sex, age, disease duration, dominant hand, and side of involvement (all $p>0.05$ ).

In all patients of the three groups, there were a statistically significant decrease of VAS and PRTEE scores and a significant increase of hand grip strength at 4 weeks of follow-up and 12 weeks of follow-up $(p<0.05$, for all) (Tables 2 and 4) (Fig. 2).

Further, ESWT and CS groups showed a more decrease in VAS score than PT group at 4 weeks of followup with no significant difference regarding VAS between the three groups at 12 weeks of follow-up. Moreover, ESWT group showed a more decrease in PRTEE score

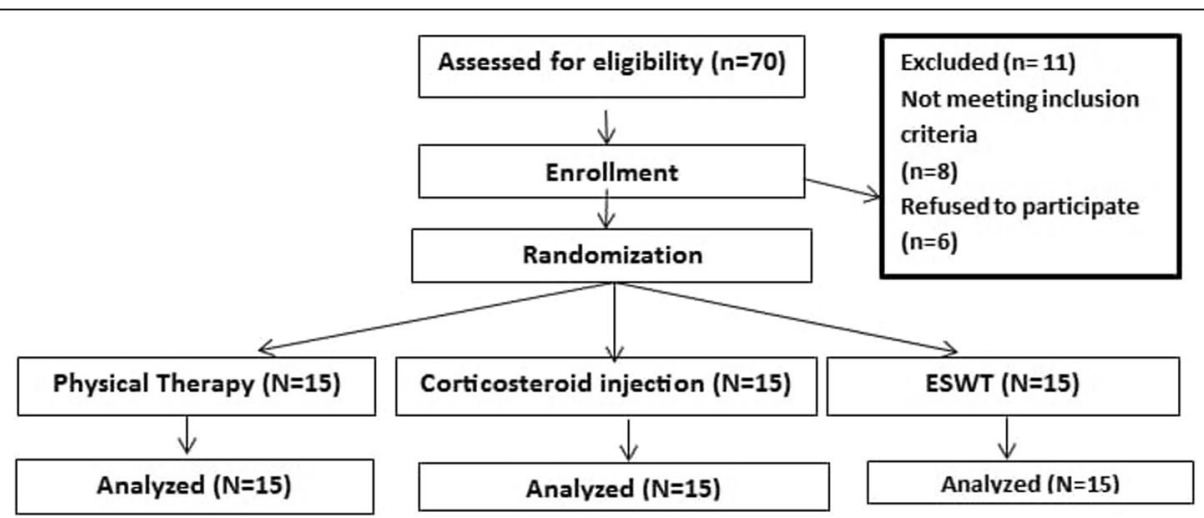

Fig. 1 Flowchart diagram for the participants who were randomized into three groups as receiving physical therapy, corticosteroid injection, and extracorporeal 
Table 1 Comparison between the three groups regarding demographic data of included patients

\begin{tabular}{|c|c|c|c|c|c|}
\hline \multirow[t]{2}{*}{ Variable } & & \multirow{2}{*}{$\begin{array}{l}\text { Corticosteroid } \\
\text { No. }=15\end{array}$} & \multirow{2}{*}{$\begin{array}{l}\text { Shock wave } \\
\text { No. }=15\end{array}$} & physiotherapy & \multirow[t]{2}{*}{$p$ value } \\
\hline & & & & No. $=15$ & \\
\hline Age & Mean \pm SD & $46.00 \pm 6.02$ & $44.73 \pm 6.06$ & $49.33 \pm 6.40$ & 0.120 \\
\hline \multirow[t]{2}{*}{ Sex } & Male & $8(53.3 \%)$ & $9(60.0 \%)$ & $8(53.3 \%)$ & 0.914 \\
\hline & Female & 7 (46.7\%) & $6(40.0 \%)$ & 7 (46.7\%) & \\
\hline \multirow[t]{2}{*}{ Side } & Left & $9(60.0 \%)$ & $9(60.0 \%)$ & $9(60.0 \%)$ & 1.000 \\
\hline & Right & $6(40.0 \%)$ & $6(40.0 \%)$ & $6(40.0 \%)$ & \\
\hline \multirow[t]{2}{*}{ Dominant hand } & Left & 1 (6.67 \%) & $0(0 \%)$ & $2(13.33 \%)$ & 0.342 \\
\hline & Right & 14 (93.3\%) & 15 (100\%) & $13(86.67 \%)$ & \\
\hline $\begin{array}{l}\text { Duration of illness } \\
\text { (months) }\end{array}$ & Mean \pm SD & $8.00 \pm 2.90$ & $8.20 \pm 2.88$ & $7.07 \pm 3.33$ & 0.558 \\
\hline
\end{tabular}

$p$ value $>0.05$, non significant (NS); $p \leq 0.05$, significant (S)

than the other two groups at 4 and 12 weeks of followup. With respect to grip strength measurement, there was no significant difference among the three groups at 4 and 12 weeks of follow-up (Tables 2, 3, and 4) (Figs. 2 and 3).

\section{Discussion}

In our study, the highly significant effectiveness of ESWT on pain and functional disability agreed with Maffulli et al. [11], who did a study on 59 patients with LE receiving 3 sessions of ESWT sessions and reported a significant improvement regarding the VAS score, PRTEE score, and HGS after 3, 6, 12, and 24 months of follow-up.

In contrast, Buchbinder et al. [12] did a systematic review and reported that there was a proof that extracorporeal shock wave therapy provided no or little effect in pain and function in LE patients.

The reason for the conflicting results of ESWT on LE could be the changes in the pulses number, applied duration, frequency, treatment interval, and different devices applied, relying on the different protocols applied in treatment.

This is because when the literature is revised, it is seen that ESWT does not have a standard protocol used for treatment of LE. Rompe et al. [13] used ESWT with 1000 pulses and $0.08 \mathrm{~mJ} / \mathrm{mm}^{2}$ low energy intensity, for three sessions in the placebo-controlled study and reported no significant changes among both groups after treatment but, when Rompe et al. [14] used ESWT with 2000 pulses and $0.09 \mathrm{~mJ} / \mathrm{mm} 2$ per a week for three sessions, they reported superiority of ESWT in pain, hand grip strength and function outcomes after 3 months and 12 months of follow-up. And this supports the superior effect of ESWT protocol used in our study which consisted of 3 sessions with 2000 pulses, 16 frequency, 1.6 bar for 3 weeks with 1-week interval.

Meanwhile, the disease duration in our study ranged from 3 to 12 months with mean 7.76 months. Alvarez et al. [15] found that patients with symptoms of long duration respond better to ESWT as they have diseased tissue and changes of nociceptors that are treated by ESWT.

The highly significant effect of CS injection in our study was in parallel to Smidt et al. study [4] that included thirteen studies, to evaluate the effectiveness of CS injection compared to placebo injection, local anesthetic injection, or another conservative treatment in LE. For short-term outcomes ( $\leq 6$ weeks), there were significant differences that were observed on pain relief,

Table 2 Comparison between the three groups regarding PRTEE score

\begin{tabular}{|c|c|c|c|c|c|}
\hline \multirow[t]{2}{*}{ PRTEE } & & \multirow{2}{*}{$\begin{array}{l}\text { Corticosteroid } \\
\text { No. }=15\end{array}$} & \multirow{2}{*}{$\begin{array}{l}\text { Shock wave } \\
\text { No. }=15\end{array}$} & \multirow{2}{*}{$\begin{array}{l}\text { physiotherapy } \\
\text { No. }=15\end{array}$} & \multirow[t]{2}{*}{$p$ value } \\
\hline & & & & & \\
\hline Before & Mean \pm SD & $74.40 \pm 6.80$ & $69.47 \pm 8.94$ & $69.00 \pm 9.84$ & 0.177 \\
\hline After 4 weeks & Mean \pm SD & $41.87 \pm 11.61$ & $30.87 \pm 9.16$ & $39.00 \pm 9.55$ & 0.014 \\
\hline After 12 weeks & Mean \pm SD & $31.80 \pm 9.91$ & $14.33 \pm 5.18$ & $23.87 \pm 5.96$ & 0.000 \\
\hline \multicolumn{2}{|c|}{ Repeated measure ANOVA test } & 129.373 & 452.896 & 335.543 & \\
\hline \multicolumn{2}{|l|}{$p$ value } & 0.000 & 0.000 & 0.000 & \\
\hline \multirow[t]{2}{*}{ Mean difference } & 4 weeks & $-32.53 \pm 10.69$ & $-38.60 \pm 7.77$ & $-30.00 \pm 7.43$ & 0.030 \\
\hline & 12 weeks & $-42.60 \pm 8.28$ & $-55.13 \pm 8.09$ & $-45.13 \pm 7.63$ & 0.000 \\
\hline
\end{tabular}

PRTEE patient related tennis elbow evaluation; $p$ value $>0.05$, non significant (NS); $p$ value $\leq 0.05$, significant (S) 


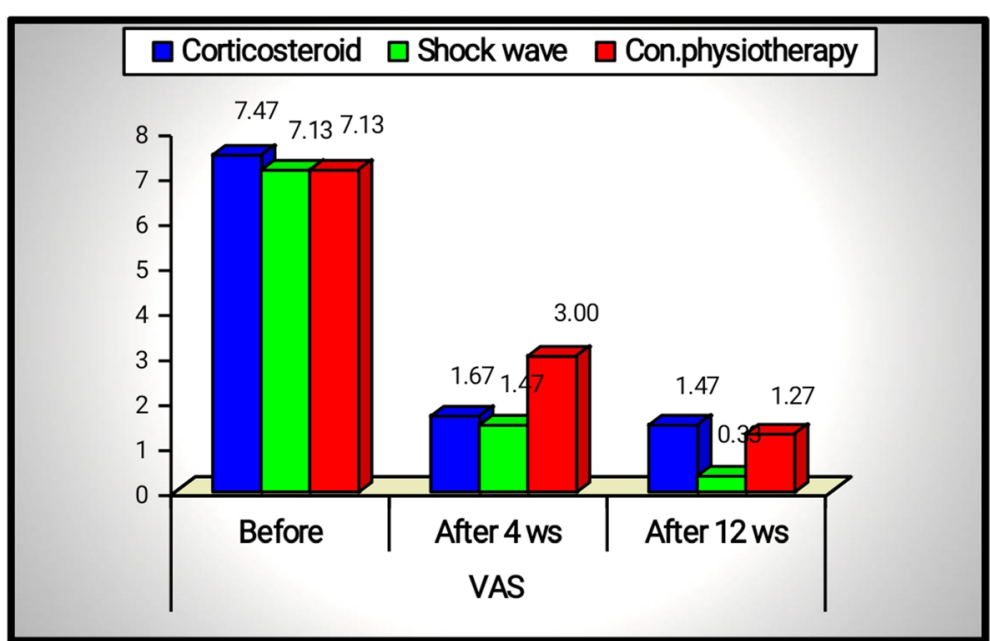

Fig. 2 Follow-up of VAS in the three groups

global improvement, and hand grip strength for CS injection compared to other treatment options [4]. On the other hand, Lindenhovius et al. [16] compared CS injection to placebo injection and found non-significant changes in the pain and functional disability scores, in the short-term and long-term follow-up.

In contrast to our study, Haker and Lundeberg [17] recorded a non-significant change in the treatment of LE between ultrasound-treated group and sham ultrasoundtreated group using either continuous or pulsed ultrasound. While in 2010, Akın et al. [18] reported significantly improved recovery in patients with LE treated with ultrasound compared with those treated with sham ultrasound.

We used pulsed ultrasound in our study due of its stable cavitations, mechanical effects, and micro streaming were thought to enhance the regeneration and healing of tissues. Likewise, Kachanathu and Vellapallil [19] compared the effectiveness of pulsed ultrasound therapy (PUST) and continuous ultrasound therapy (CUST) in the treatment of LE and reported

Table 3 Post hoc test between the three groups regarding PRTEE score

\begin{tabular}{llll}
\hline & \multicolumn{3}{l}{ Post hoc analysis by LSD } \\
\cline { 2 - 4 } & $p 1$ & $p 2$ & $p 3$ \\
\hline PRTEE after 4 weeks & 0.005 & 0.444 & 0.034 \\
PRTEE after 12 weeks & 0.000 & 0.013 & 0.001 \\
Mean difference 4 weeks & 0.046 & 0.458 & 0.004 \\
Mean difference at 12 weeks & 0.000 & 0.392 & 0.002 \\
\hline
\end{tabular}

$p 1$ corticosteroid versus shock wave, $p 2$ corticosteroid versus physiotherapy $p 3$ shock wave versus physiotherapy, LSD least significant difference that PUST combined with physiotherapy exercises for LE patients have better outcome than CUST.

Some studies in the literature compared the effectiveness of ESWT with injectable steroids or conventional physiotherapy regarding the pain and functional scores. Beyazal and Devrimsel [9] compared the effectiveness of local CS injection and ESWT in LE patients and reported equally significant improvement in all patients of both groups at 4 weeks post-treatment and better results in ESWT group at 12 weeks of follow-up indicating better long-term outcome of ESWT.

Meanwhile, Crowther et al. [20] conducted a study involving 73 patients who received either CS injection or ESWT. The CS injection group received triamcinolone $(20 \mathrm{mg})$ with $1.5 \mathrm{ml}$ of lidocaine (1\%). They found reduction of the VAS score by $82 \%$ in the CS group and by $49 \%$ in the ESWT group at 12 weeks of follow-up.

This may be explained by the different types of steroid used as the steroid injected in our study was methylprednisolone which is slightly water soluble and has a shorter duration of action (1-5 weeks) than triamcinolone which is a relative water insoluble and has a long duration of action (several weeks) [21]. Awori [22] reported that a more water-insoluble preparation is preferable in suppression of chronic inflammatory conditions, so CS reported greater short term analgesic effect in our study.

Lizis [23] compared the analgesic impacts of extracorporeal shock wave therapy and therapeutic ultrasound (US) in patients with chronic LE and recorded that there was a highly significant reduction of pain score (VAS ) in the group treated with ESWT more 
Table 4 Comparison between three groups regarding HGS

\begin{tabular}{|c|c|c|c|c|c|}
\hline \multicolumn{2}{|c|}{ Hand grip strength (HGS) } & \multirow{2}{*}{$\begin{array}{l}\text { Corticosteroid } \\
\text { No. }=15\end{array}$} & \multirow{2}{*}{$\begin{array}{l}\text { Shock wave } \\
\text { No. }=15\end{array}$} & \multirow{2}{*}{$\begin{array}{l}\text { Physiotherapy } \\
\text { No. }=15\end{array}$} & \multirow[t]{2}{*}{$p$ value } \\
\hline & & & & & \\
\hline Before & Mean \pm SD & $12.47 \pm 4.85$ & $14.93 \pm 6.33$ & $11.40 \pm 3.92$ & 0.167 \\
\hline After 4 weeks & Mean \pm SD & $29.87 \pm 7.58$ & $30.13 \pm 9.40$ & $28.13 \pm 11.19$ & 0.823 \\
\hline After 12 weeks & Mean \pm SD & $34.00 \pm 14.58$ & $44.93 \pm 13.20$ & $34.80 \pm 11.83$ & 0.052 \\
\hline \multicolumn{2}{|c|}{ Repeated measure ANOVA test } & 44.171 & 77.531 & 59.574 & \\
\hline \multicolumn{2}{|l|}{$p$ value } & 0.000 & 0.000 & 0.000 & \\
\hline \multirow[t]{2}{*}{ Mean difference } & 4 weeks & $17.40 \pm 5.65$ & $15.20 \pm 7.35$ & $16.73 \pm 8.99$ & 0.712 \\
\hline & 12 weeks & $21.53 \pm 12.17$ & $30.0 \pm 12.55$ & $23.40 \pm 10.51$ & 0.130 \\
\hline
\end{tabular}

$p$ value $>0.05$, non significant (NS); $p$ value $\leq 0.05$, significant $(\mathrm{S})$

than the US group after treatment directly and 3 months after treatment.

Murtezani et al. [24] compared CS injection with physiotherapy modalities (ultrasound and exercise) for treating chronic LE and reported that the CS group was significantly improved than the PT group regarding VAS score reduction at 6 weeks of follow-up, and this difference was no longer evident by 12 weeks.

In our study, we applied ESWT without local anesthesia as Pettrone and McCall [6] demonstrated that local anesthesia may alter the effect of shockwave on the tissue, or simply prevent treating the most painful area due to the analgesic effect of the anesthesia.

All patients of our study used counterforce forearm strap and it was suggested that it played an important role in improvement of pain and function in $\mathrm{LE}$ as it permits the muscle to relieve in the early stage and supply proprioceptive chip in the chronic stage. Vellilappilly et al. [25] review revealed that orthosis alone or in combination with routine physical therapy can be considered as an evidence-based treatment strategy for patients with LE.

Our patients did not record any side effects except transient pain in the treated elbow that was considered as a guiltless adverse effect and they did not stop the therapy. Tosti et al. [26] observed localized redness of the skin and tiny hematomas in 10 patients of 14 ones during management of LE.

Fewer number of ESWT sessions (three sessions only) besides the minimum number of physiotherapy sessions used in treatment of chronic LE (twelve sessions only) in addition to, the short evaluation period which was only 12 weeks may be considered as a limitation for the conclusive results of our study. This was because the outpatient's follow-up was limited.

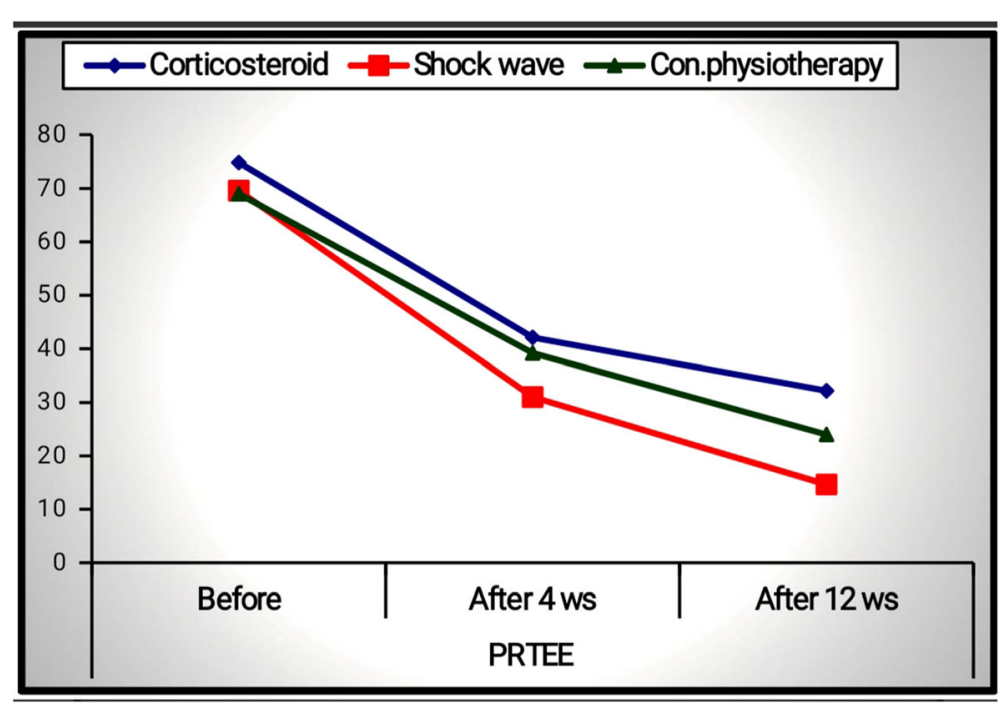

Fig. 3 Follow-up of PRTEE in the three groups 


\section{Conclusion}

Our results propose that although extracorporeal shock wave therapy, conventional physiotherapy, and corticosteroid injection were all efficient in treatment of chronic lateral epicondylitis at 12 weeks of followup. However, ESWT was superior to all other alternatives due to its effect on pain and improving function during daily-life activities at short term and long term follow-up.

\section{Abbreviations}

CUST: Continuous ultrasound therapy; ESWT: Extracorporeal shock wave therapy; HGS: Hand grip strength; CS: Corticosteroid; LE: Lateral epicondylitis; PRTEE: Patient rated tennis elbow evaluation; PT: Physiotherapy; PUST: Pulsed ultrasound therapy; RCTs: Randomized controlled trials; TENS: Transcutaneous electrical nerve stimulation; US: Ultrasound; VAS: Visual analog scale

\section{Acknowledgements}

Not applicable.

\section{Authors' contributions}

MMA, made the design of the work, interpretation of data, and the creation of new software used in the work. AAKZ was shared in the design of the work and interpretation of data. SEI was shared in the design of the work and interpretation of data. All authors agreed both to be personally accountable for the author's own contributions and to ensure that questions related to the accuracy or integrity of any part of the work, even ones in which the author was not personally involved, are appropriately investigated, resolved, and the resolution documented in the literature. The authors have read and approved the manuscript.

\section{Funding}

No funding.

\section{Availability of data and materials}

Available.

\section{Ethics approval and consent to participate}

This study was reviewed and approved by the Research Ethics Committee of the Faculty of Medicine, Ain Shams University Institutional Review Board.

Written informed consents were taken from all participants.

The committee reference number is not available.

\section{Consent for publication}

Obtained from all participants of the study.

\section{Competing interests}

The authors declare that they have no competing interests.

Received: 14 April 2020 Accepted: 14 June 2020

Published online: 29 October 2020

\section{References}

1. Brummel J, Baker CL III, Hopkins R, Baker CL Jr (2014) Epicondylitis: lateral. Sports Med Arthrosc Rev 22(3):e1-e6

2. Ahmad Z, Siddiqui N, Malik SS, Abdus-Samee M, Tytherleigh-Strong G, Rushton N (2013) Lateral epicondylitis: a review of pathology and management. Bone Jnt J 95(9):1158-1164

3. Walz DM, Newman JS, Konin GP, Ross G (2010) Epicondylitis: pathogenesis, imaging, and treatment. Radiographics 30(1):167-184

4. Smidt N, Van Der Windt DAWM, Assendelft WJJ, Devillé WLJM, Korthals-de Bos IBC, Bouter LM (2002) Corticosteroid injections, physiotherapy, or a waitand-see policy for lateral epicondylitis: a randomised-controlled-trial. Lancet 359(9307):657-662

5. Pettrone FA, McCall BR (2005) Extracorporeal shock wave therapy without local anesthesia for chronic lateral epicondylitis. JBJS. 87(6):1297-1304

6. Trentini R, Mangano T, Repetto I, Cerruti P, Kuqi E, Trompetto C, Franchin F (2015) Short- to mid-term follow-up effectiveness of US-guided focal extracorporeal shock wave therapy in the treatment of elbow lateral epicondylitis. Musculoskelet Surg 99(Suppl 1):S91-S97

7. Dundar U, Turkmen U, Toktas H, Ulasli AM, Solak O (2015) Effectiveness of high-intensity laser therapy and splinting in lateral epicondylitis: a prospective, randomized, controlled study. Lasers Med Sci 30(3):1097-1107

8. Beyazal MS, Devrimsel G (2015) Comparison of the effectiveness of local corticosteroid injection and extracorporeal shock wave therapy in patients with lateral epicondylitis. J Phys Sci 27(12):3755-3758

9. Yalvaç B, Mesci N, Külcü DG, Yurdakul OV (2018) Comparison of ultrasound and extracorporeal shock wave therapy in lateral epicondylosis. Acta Orthop Traumatol Turc 52(5):357-362

10. Roberts HC, Denison HJ, Martin HJ, Patel HP, Syddall H, Cooper C, Sayer AA (2011) A review of the measurement of grip strength in clinical and epidemiological studies: towards a standardised approach. Age Ageing 40(4):423-429

11. Maffulli G, Iuliano E, Padulo J, Rompe J, Gerdesmeyer L, Maffulli N (2018) Extracorporeal shock wave therapy in the treatment of tennis elbow. Muscles Ligaments Tendons J 8(3):423-429

12. Buchbinder R, Green S, Youd JM, Assendelft WJ, Barnsley L, Smidt N (2005) Shock wave therapy for lateral elbow pain. Cochrane Database Syst Rev 4

13. Rompe JD, Hopf C, Küllmer K, Heine J, Bürger R (1996) Analgesic effect of extracorporeal shock-wave therapy on chronic tennis elbow. J Bone Jnt Surg Brit 78(2):233-237

14. Rompe JD, Meurer A, Nafe B, Hofmann A, Gerdesmeyer L (2005) Repetitive low energy shock wave application without local anesthesia is more efficient than repetitive low energy shock wave application with local anesthesia in the treatment of chronic plantar fasciitis. J Orthopaed Res 23(4):931-941

15. Alvarez RG, Ogden JA, Jaakkola J, Lee Cross G (2003) Symptom duration of plantar fasciitis and the effectiveness of Orthotripsy. Foot Ankle Int 24(12): 916-921

16. Lindenhovius A, Henket M, Gilligan BP, Lozano-Calderon S, Jesse BJ, David R (2008) Injection of dexamethasone versus placebo for lateral elbow pain: a prospective, double-blind, randomized clinical trial. J Hand Surg 33(6):909919

17. Haker E, Lundeberg T (1991) Pulsed ultrasound treatment in lateral epicondylitis. Scand J Rehabil Med 23(3):115-118

18. Akın C, Öken Ö, Füsun Köseoğlu B (2010) Short-term effectiveness of ultrasound treatment in patients with lateral epicondylitis: randomized, single-blind, placebo-controlled, prospective study. Turk J Rheumatol 25(2)

19. Kachanathu SJ, Vellapallil DMSNS (2013) Pulsed versus continuous ultrasound therapy: as a management of lateral epicondylitis. Innov J Med Health Sci 3:242-245

20. Crowther MAA, Bannister GC, Huma H, Rooker GD (2002) A prospective, randomised study to compare extracorporeal shockwave therapy and injection of steroid for the treatment of tennis elbow. The Journal of bone and joint surgery. Brit Vol 84(5):678-679

21. Sakeni RA, AI-Nimer MSM (2007) Comparison between intraarticular triamcinolone acetonide and methylprednisolone acetate injections in treatment of frozen shoulder. Saudi Med J 28(5):707-712

22. Awori KO (2009) Local corticosteroid injections: rational use in common orthopaedic problems. Ann Afr Surg 4(1)

23. Lizis P (2015) Analgesic effect of extracorporeal shock wave therapy versus ultrasound therapy in chronic tennis elbow. J Phys Ther Sci 27(8):2563-2567

24. Murtezani A, Ibraimi Z, Vllasolli TO, Sllamniku S, Krasniqi S et al (2015) Exercise and therapeutic ultrasound compared with corticosteroid injection for chronic lateral epicondylitis: a randomized controlled trial. Ortopedia Traumatologia Rehabilitacja 17(4):351-357

25. Vellilappily DV, Rai HR, Varghese J, Renjith V (2017) Counterforce orthosis in the management of lateral epicondylitis. J Ayub Med Coll Abbottabad 29(2): 328-334

26. Tosti R, Jennings J, Sewards JM (2013) Lateral epicondylitis of the elbow. Am J Med 126(4):357-3e1

\section{Publisher's Note}

Springer Nature remains neutral with regard to jurisdictional claims in published maps and institutional affiliations. 